\title{
The relation between upper extremity joint involvement and grip force in early rheumatoid arthritis: a retrospective study
}

\author{
Maria Rydholm ${ }^{1,2}$ (1) Ingegerd Wikström ${ }^{1,2} \cdot$ Sofia Hagel ${ }^{3,4} \cdot$ Lennart T. H. Jacobsson $^{1,5} \cdot$ Carl Turesson $^{1,2} \mathbb{C}$
}

Received: 17 July 2019 / Accepted: 29 August 2019 / Published online: 7 September 2019

(c) The Author(s) 2019

\begin{abstract}
To investigate the relation between joint involvement in the upper extremities and grip force in patients with early rheumatoid arthritis (RA). An inception cohort of 225 patients with early RA was followed according to a structured protocol. The same rheumatologist assessed all patients for swollen joints and joint tenderness. Grip force was measured (Grippit; AB Detektor, Gothenburg, Sweden) at the same visit. Average grip force values for the dominant hand were expressed as \% of expected, based on age- and sex-specific reference values from the literature. Associations between grip force and current synovitis or tenderness of individual joints, and other disease parameters measured at the same visit, were examined. Patients with current synovitis of the wrist joint or $\geq 1$ metacarpophalangeal (MCP) joint of the dominant hand had a significantly lower grip force at inclusion, at 1 year and at 5 years. Proximal interphalangeal joint tenderness and MCP joint tenderness were consistently associated with reduced grip force. In multivariate analysis, extensive MCP joint synovitis was associated with lower grip force at inclusion ( $\beta-2.8 \%$ per joint; $95 \% \mathrm{CI}-5.3$ to -0.4$)$, and also at the 1-year follow-up. Patient reported pain scores and erythrocyte sedimentation rates had independent negative associations with grip force at all time points. In patients with early RA, extensive synovitis of the MCP joints was associated with reduced grip force, independently of other upper extremity joint involvement. Pain and inflammation have effects on hand function beyond those mediated by local synovitis.
\end{abstract}

Keywords Early rheumatoid arthritis $\cdot$ Grip force $\cdot$ Joint tenderness $\cdot$ Synovitis

\section{Abbreviations}

ACR American College of Rheumatology

ADL Activities of daily living

CI Confidence intervals

CRP C-reactive protein

DAS28 Disease activity score for 28 joints

DASH Disabilities of the Arm, Shoulder and Hand Questionnaire

Electronic supplementary material The online version of this article (https://doi.org/10.1007/s00296-019-04438-x) contains supplementary material, which is available to authorized users.

Carl Turesson

carl.turesson@med.lu.se

Maria Rydholm

Maria.Rydholm@skane.se

Ingegerd Wikström

Ingegerd.Wikstrom.se@gmail.com

Sofia Hagel

Sofia.Hagel@skane.se

Lennart T. H. Jacobsson

Lennart.Jacobsson@gu.se
DMARDs Disease modifying anti rheumatic drugs

ESR Erythrocyte sedimentation rate

HAQ Health Assessment Questionnaire

HAQ-DI Health Assessment Questionnaire Disability Index

IQR Interquartile range

MCP Metacarpophalangeal joints

N Newton

PIP Proximal interphalangeal joints

RA Rheumatoid arthritis

VAS Visual Analogue Scale

1 Rheumatology, Department of Clinical Sciences, Lund University, Malmö, Sweden

2 Department of Rheumatology, Skåne University Hospital, Malmö, Sweden

3 Department of Rheumatology, Skåne University Hospital, Lund, Sweden

4 Rheumatology, Department of Clinical Sciences, Lund University, Lund, Sweden

5 Department of Rheumatology and Inflammation Research, Sahlgrenska Academy at Gothenburg University, Gothenburg, Sweden 


\section{Background}

Rheumatoid arthritis (RA) is characterized by chronic synovitis, in which the highly cellular inflammatory pannus tissue infiltrates both the cartilage, ligaments and tendons. This leads to erosion of the cartilage, gradual bone destruction, disruption of ligaments and impaired tendon glide that contribute to stiffness, pain and finally joint deformities [1]. Deformities in early untreated RA are initially passively correctable, but may with time lead to limited motion, and finally to fixed deformities [2]. RA typically involves the joints in the distal upper extremity, and more than $80 \%$ of the patients have dysfunction in the hands [3]. Joint inflammation and joint deformity both contribute to functional limitations in RA [4]. Progressive joint damage and disability lead to difficulties in performing activities of daily living (ADL). Symptoms due to wrist and hand involvement, and related limitations in function and ADL are common in both early and late RA $[5,6]$.

In comparison with age- and sex matched healthy populations, patients with RA have been shown to have reduced grip force [7-13] and finger extension force [10,13]. We have recently reported that although grip force improved over time in patients with early RA, most patients in a community-based inception cohort of patients with RA still had $<60 \%$ of the expected grip force values, based on age and sex-specific reference values, 5 years after diagnosis [12]. In the evaluation of clinical trials, grip force, swollen joint count, patient reported pain and functional status measured by the Health Assessment Questionnaire (HAQ) [14] were all found to be outcome measures with intermediate responsiveness in patients with RA [15].

Several components contribute to grip force. Different muscle groups of the distal upper extremities produce the power, for instance the forearm flexor activation and the extensor synergist. It is important that the wrist is stabilized by the extensor muscles when the hand is gripping with force [16]. Wrist deformities are known to have a significant major impact on hand function [17-19.].

Furthermore, muscle strength in the upper extremity has been proposed to correlate with grip force [20]. Already 1.5 years after disease onset, patients with RA have been shown to have significantly reduced shoulder muscle strength in comparison with age-matched healthy controls [11]. There were significant associations between grip force, the Disabilities of the Arm, Shoulder and Hand (DASH) questionnaire score and shoulder muscle strength of the dominant arm [11]. A study of patients with early RA (disease duration of $\leq 12$ months) showed that the lean mass of arms and legs was significantly reduced in both women and men compared to age-matched controls [21].
In the upper extremity, shoulder, elbow and wrist were the three joints with the greatest contributions to HAQ scores in patients with RA [22]. However, there are limited data on the relation between the involvement of specific joints and objective measures of hand function. Such information could be useful for targeted rehabilitation and other interventions. The potential importance of such findings is underlined by the demonstrated success of structured rehabilitation programs in RA [23, 24]. For example, in the randomized controlled SARAH trial, a tailored hand exercise program was shown to improve hand function in patients with RA [24].

The objective of this study was to investigate the relation between synovitis of different joints in the upper extremities and grip force in patients with early RA.

\section{Patients and methods}

\section{Patients}

An inception cohort of patients with early RA (symptom duration $\leq 12$ months) recruited in 1995-2005, was investigated. The patients were diagnosed with RA by a rheumatologist and fulfilled the 1987 American College of Rheumatology (ACR) classification criteria for RA [25]. The study included individuals from a defined area, the city of Malmö, Sweden (population 260,000 in 2000). Patients were recruited from the rheumatology outpatient clinic of Malmö University Hospital, which was the only hospital serving the city, and from the four rheumatologists in private practice in Malmö. All patients gave their written informed consent to participate, and the study was approved by the Regional Ethical Review Board for southern Sweden (Lund, Sweden).

\section{Clinical assessment}

Patients were managed according to usual care, with no prespecified protocol for pharmacotherapy or rehabilitation. In a structured follow-up program, all patients were examined by the same rheumatologist. Visits were scheduled at 6,12 and 24 months as well as 5 years after inclusion. Using a standardized protocol, individual joints were assessed as swollen/ not swollen and tender/not tender. Disability was assessed using the Health Assessment Questionnaire Disability Index (HAQ-DI) [14]. Patient reported pain and patients' global assessment of disease activity were assessed using Visual Analogue Scales (VAS; scale 0-100). Information on treatment was obtained as previously described [12]. Blood samples were obtained at the visit when the joint assessment was performed (within $1 \mathrm{~h}$ ). C-reactive protein (CRP) and the Erythrocyte Sedimentation Rate (ESR) were analyzed using 
standard methods at the Department of Clinical Chemistry, Malmö University Hospital.

\section{Assessment of grip force}

Grip force (Newton, $N$ ) was measured by using the electronic instrument Grippit (AB Detektor, Gothenburg, Sweden). This was performed at the same visit as the joint assessment (within $1 \mathrm{~h}$ ). All Grippit procedures were performed after 9.20 a.m. to limit the impact of morning stiffness. The patient was seated comfortably in a chair without armrests, with the shoulder, arm and hand in standard positions as previously described [26]. The other arm was resting on the table. Standardized instructions were given. When using this procedure, the test-retest scores for Grippit measures have been demonstrated to be high [26]. Nordenskiöld et al. reported a methodological error of $18 \%$ in patients with RA [26] and in studies of healthy children, intraclass correlation coefficients of $0.78-0.96$ were found [27].

The grip force was measured alternately in the dominant hand and the non-dominant hand three times, and the mean of the three measurement values from each hand was used. Average values of the ten second uninterrupted grip were obtained, as previously described [12]. Average grip force values of the dominant hand at inclusion and at the 1-year and 5-year follow-up visits were compared to the expected, based on age- and sex-specific reference values from a convenience sample from a cross-sectional study of volunteers in the region of Oslo, Norway [28]. Grip force values for each patient were expressed as \% of the expected, based on the reference values.

\section{Statistics}

Grip force values (\% of expected values of the dominant hand) in those with vs without current synovitis and with vs without current tenderness of individual joints in the dominant arm at each time point were compared using Student's $t$ test.

Linear regression analysis was used to further explore the relation between upper extremity joint involvement in individual joints of the dominant arm and grip force (\% of expected values of the dominant hand). The presence/ absence of synovitis/tenderness in each joint or joint group [i.e. proximal interphalangeal (PIP) joints and metacarpophalangeal (MCP) joints] were included as covariates. In addition, the impact of the number of swollen/tender MCP $(0-5)$ and PIP joints $(0-5)$ was assessed. Furthermore, associations with VAS pain and ESR were explored in separate models. To examine potential synergistic effects, interactions between involvement (synovitis or joint tenderness, assessed separately) of different joints were tested, with grip force (\% of expected values of the dominant hand) as the dependent variable. Covariates with $p$ values of $<0.10$ in the bivariate models were included in multivariate models. Collinearity between covariates was examined using Spearman's test. In cases of major collinearity (e.g. presence of MCP synovitis and number of swollen MCP joints, or wrist synovitis and wrist tenderness) the covariate with the strongest association with the dependent variable was selected for the multivariate analysis. The multivariate models were adjusted for significant interaction terms. In sensitivity analyses, the models were further adjusted for current glucocorticoid use.

To explore the impact of grip force on disability and overall disease impact, correlations between grip force (\% of expected values of the dominant hand) and HAQ-DI and VAS global were investigated using Pearson's test.

Statistical analyses were performed using IBM SPSS Statistics version 22.0, Armonk, NY, USA: IBM Corp.

\section{Results}

\section{Patients}

A total of 225 patients with early RA ( $71 \%$ women; mean age 60 years) were investigated. The median symptom duration at inclusion was 7 months; interquartile range (IQR) 5-10. Data on average grip force of the dominant hand were available for 200 patients at inclusion, 202 patients at 1 year, and 173 patients at 5 years (Table 1).

A majority of the patients was treated with methotrexate (Table 1). A total of $17 \%$ initiated treatment with a biologic DMARD within 5 years. At baseline, the mean average grip force of the dominant hand was $105 \mathrm{~N}$ (mean $40 \%$ of expected). This increased over time to $139 \mathrm{~N}$ (mean $57 \%$ of expected) at 5 years (Table 1).

\section{Frequency of joint involvement in early RA: overtime}

Among patients with data on average grip force at inclusion $53 \%$ had synovitis of $\geq 1$ PIP joint in the dominant hand, whereas synovitis of MCP, wrist, elbow and shoulder joints on the dominant side was observed in $79 \%, 64 \%, 8 \%$ and $7 \%$, respectively (Table 2).

Whereas tenderness was more common compared to clinical synovitis in the shoulder, the reverse was the case for wrist, MCP and PIP joints (Table 2). Proportions with current joint involvement decreased somewhat over time, in particular the prevalence of PIP joint synovitis (Table 2).

There was major collinearity between the presence of synovitis and joint tenderness in the same joint/joint group at inclusion $(r=0.30-0.56 ; p<0.001$ for all correlations), at 1 year $(r=0.32-0.59 ; p<0.001$ for all correlations) and at 5 years $(r=0.23-0.50 ; p<0.01$ for all correlations). 
Table 1 Characteristics of patients with RA and data on average grip force of the dominant hand

\begin{tabular}{llll}
\hline & Inclusion $^{\mathrm{b}}$ & 1 year $^{\mathrm{c}}$ & 5 years $^{\mathrm{d}}$ \\
\hline$N$ & $200^{\mathrm{a}}$ & $202^{\mathrm{a}}$ & $173^{\mathrm{a}}$ \\
Female sex \% $(n)$ & $70(140)$ & $71(143)$ & $71(123)$ \\
Age (years) & $59.8(14.7)$ & $60.9(14.6)$ & $64.6(14.3)$ \\
Symptom duration at inclusion (months); median (IQR) & $7(5-10)$ & $7(5-10)$ & $7(5-10)$ \\
RF positive \% (n) & $62(125)$ & $63(127)$ & $65(113)$ \\
Anti-CCP positive \% ( $n)$ & $56(99)$ & $58(104)$ & $59(89)$ \\
DAS28 (0-10) & $4.6(1.4)$ & $3.7(1.4)$ & $3.6(1.4)$ \\
HAQ (0-3) & $0.85(0.63)$ & $0.64(0.60)$ & $0.75(0.66)$ \\
Patient's global assessment (VAS 0-100) & $42(26)$ & $31(24)$ & $34(24)$ \\
Pain (VAS 0-100) & $41(27)$ & $31(24)$ & $30(24)$ \\
Swollen joint count (out of 28) & $7.9(5.0)$ & $4.8(4.1)$ & $5.2(4.9)$ \\
Tender joint count (out of 28) & $6.3(6.4)$ & $3.6(4.8)$ & $3.0(5.1)$ \\
Methotrexate treatment & $54 \%(108)$ & $63 \%(128)$ & $61 \%(106)$ \\
Other DMARD & $31 \%(62)$ & $31 \%(63)$ & $24 \%(42)$ \\
Glucocorticosteroid treatment & $40 \%(79)$ & $31 \%(64)$ & $30 \%(51)$ \\
CRP (mg/l); median (IQR) & $9(<9-23.5)$ & $<9(<9-10)$ & $<9(<9--10)$ \\
ESR (mm/h); median (IQR) & $10(20.5-42)$ & $15(8-27)$ & $16(9.5-25)$ \\
Average grip force of the dominant hand $(N)$ & $105(78)$ & $133(85)$ & $139(95)$ \\
Average grip force of the dominant hand $(\%$ of expected) & $40(26)$ & $52(28)$ & $57(30)$ \\
\hline
\end{tabular}

Values are mean (SD) unless otherwise indicated

$I Q R$ interquartile range, VAS Visual Analogue Scale

${ }^{\mathrm{a}}$ All patients with $\geq 1$ grip force measure at inclusion, 1 and 5 years

${ }^{b}$ Missing data for joint assessment $n=3$

${ }^{\mathrm{c}}$ Missing data for joint assessment $\mathrm{n}=3$

${ }^{\mathrm{d}}$ Missing data for joint assessment $\mathrm{n}=4$
Table 2 Frequency of synovitis and tender joints in the dominant hand over time in early RA

\begin{tabular}{llll}
\hline & Inclusion & 1 year & 5 years \\
\hline$N$ & 197 & 199 & 169 \\
Shoulder synovitis & $7(13)$ & $5(10)$ & $1(2)$ \\
Elbow synovitis & $8(16)$ & $6(13)$ & $4(7)$ \\
Wrist synovitis & $64(127)$ & $41(82)$ & $35(59)$ \\
$\geq 1$ MCP joint synovitis & $79(156)$ & $65(129)$ & $69(116)$ \\
$\geq 1$ PIP joint synovitis & $53(105)$ & $29(58)$ & $27(45)$ \\
No of swollen MCP joints; median & $2(1-3)$ & $1(0-2)$ & $1(0-3)$ \\
$\quad$ IQR) & & & \\
No of swollen PIP joints; median & $1(0-2)$ & $0(0-1)$ & $0(0-1)$ \\
$\quad$ IQR) & & & \\
Tender shoulder joint & $30(60)$ & $25(50)$ & $19(32)$ \\
Tender elbow joint & $12(23)$ & $4(9)$ & $2(4)$ \\
Tender wrist joint & $45(88)$ & $28(55)$ & $14(23)$ \\
$\geq 1$ tender MCP joint & $54(106)$ & $34(67)$ & $31(52)$ \\
$\geq 1$ tender PIP joint & $42(82)$ & $22(44)$ & $23(39)$ \\
No of tender MCP joints; median & $1(0-2)$ & $0(0-1)$ & $0(0-1)$ \\
$\quad$ IQR) & & & \\
No of tender PIP joints; median & $0(0-2)$ & $0(0-0)$ & $0(0-0)$ \\
$\quad$ IQR) & & & \\
\hline
\end{tabular}

Values are \% ( $n$ ) unless otherwise indicated
There was also major collinearity between presence of synovitis in MCP joints and the number of MCP joints with synovitis $(r=0.74-0.86 ; p<0.001)$ and the presence of PIP synovitis and the number of PIP joints with synovitis $(r=0.92-0.99 ; p<0.001)$ at all time points, and similar findings for joint tenderness (MCP: $r=0.93-0.98, p<0.001$; PIP: $r=0.96-0.99 ; p<0.001)$.

\section{Associations between joint involvement and grip force: bivariate analyses}

Current synovitis of the wrist joint or $\geq 1 \mathrm{MCP}$ joint of the dominant hand were associated with a significantly lower grip force at inclusion (Fig. 1a) as well as at 1 year (Fig. 1b) and 5 years (Fig. 1c). There were similar trends for PIP and elbow synovitis, although these did not reach statistical significance (Fig. 1a-c). The presence of joint tenderness was consistently associated with a significantly reduced grip force, except for elbow tenderness at 5 years (Fig. 2a-c).

In linear regression models, there were also negative associations for the number of swollen MCP joints, the number of swollen PIP joints, the number of tender MCP joints, the number of tender PIP joints, VAS pain and ESR with grip force at inclusion (Table 3). Similar associations 
Fig. 1 Grip force in patients with early RA — by current synovitis. Average grip force (\% of expected, dominant hand) in patients with early RA, by current synovitis of individual joints/joint groups at the dominant side. Mean values with $95 \%$ confidence intervals. $p$ values represent comparisons of patients with vs without synovitis for each joint/joint group. *Significant differences $(p<0.05)$. a Inclusion. Shoulder: $p=0.41$; elbow: $p=0.06$; wrist: $p<0.001 *$; metacarpophalangeal (MCP) joint $(\geq 1): p=0.001 *$; proximal interphalangeal (PIP) joint $(\geq 1): p=0.13$. b 1 -Year followup. Shoulder: $p=0.10$; elbow: $p=0.18$; wrist: $p=0.006^{*}$; MCP joint $(\geq 1): p=0.001^{*}$; PIP joint $(\geq 1): p=0.07$. $\mathbf{c}$ 5-Year follow-up. Shoulder: $p=0.049 *$; elbow: $p=0.15$; wrist: $p=0.001^{*} ;$ MCP joint $(\geq 1): p=0.01 * ;$ PIP joint $(\geq 1)$ : $p=0.10$
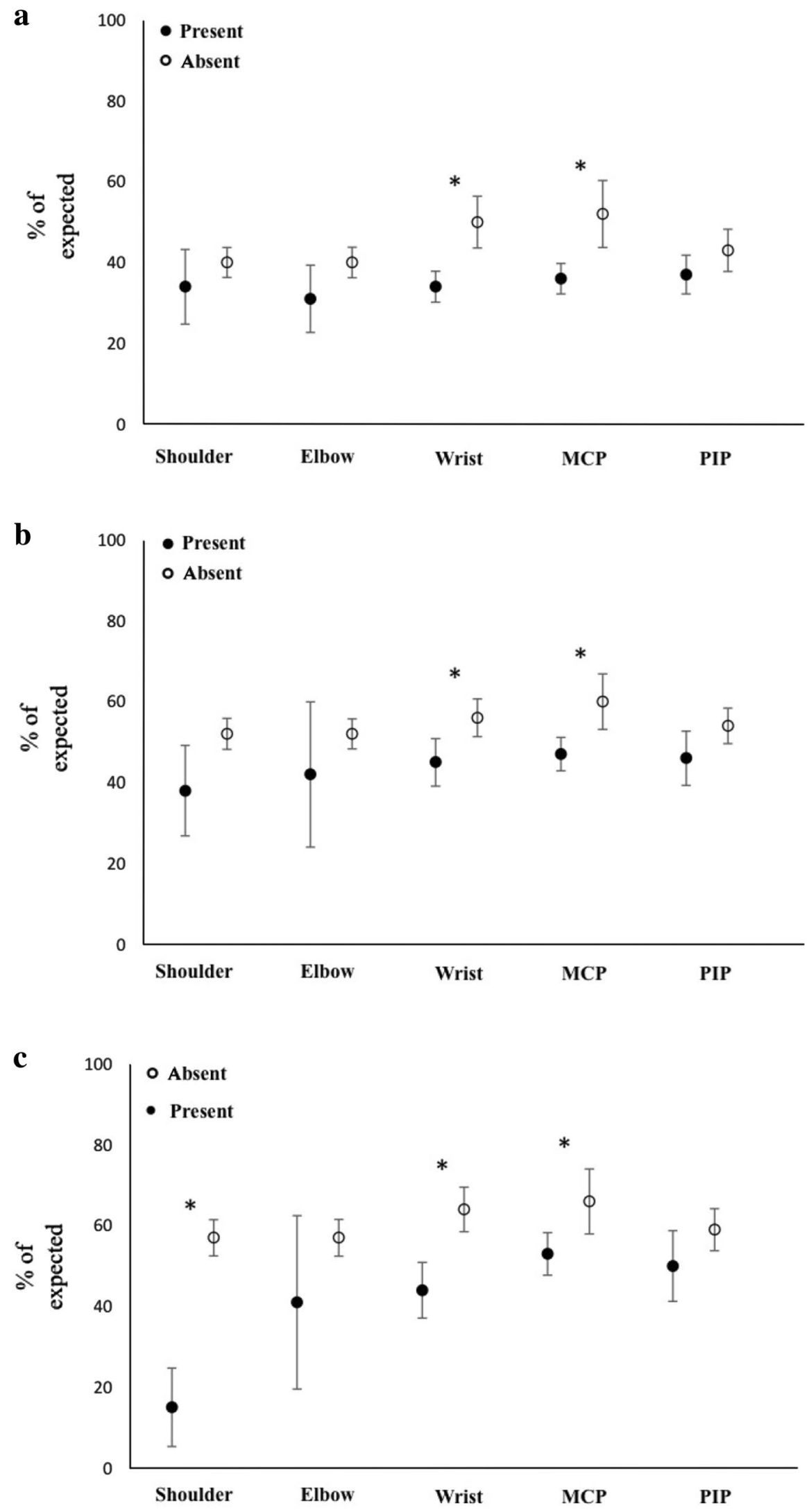
Fig. 2 Grip force in patients with early RA — by current joint tenderness. Average grip force (\% of expected, dominant hand) in patients with early

$\mathrm{RA}$, by the tenderness of individual joints/joint groups at the dominant side. Mean values with $95 \%$ confidence intervals. $p$ values represent comparisons of patients with vs without tenderness for each joint/joint group. *Significant differences $(p<0.05)$. a Inclusion. Shoulder: $p=0.06$; elbow: $p=0.008^{*}$; wrist: $p=0.002 *$; metacarpophalangeal (MCP) joint $(\geq 1)$ : $p<0.001^{*}$; proximal interphalangeal (PIP) joint $(\geq 1)$ : $p=0.003^{*}$. b 1-Year follow-up. Shoulder: $p=0.01^{*}$; elbow: $p=0.01$ *; wrist: $p<0.001 *$; MCP joint $(\geq 1): p<0.001 *$; PIP joint $(\geq 1): p<0.001^{*}$. c 5-year follow-up. Shoulder: $p=0.001 *$; elbow: $p=0.21$; wrist: $p<0.001^{*} ;$ MCP joint $(\geq 1): p=0.007^{*} ;$ PIP joint $(\geq 1): p=0.02 *$
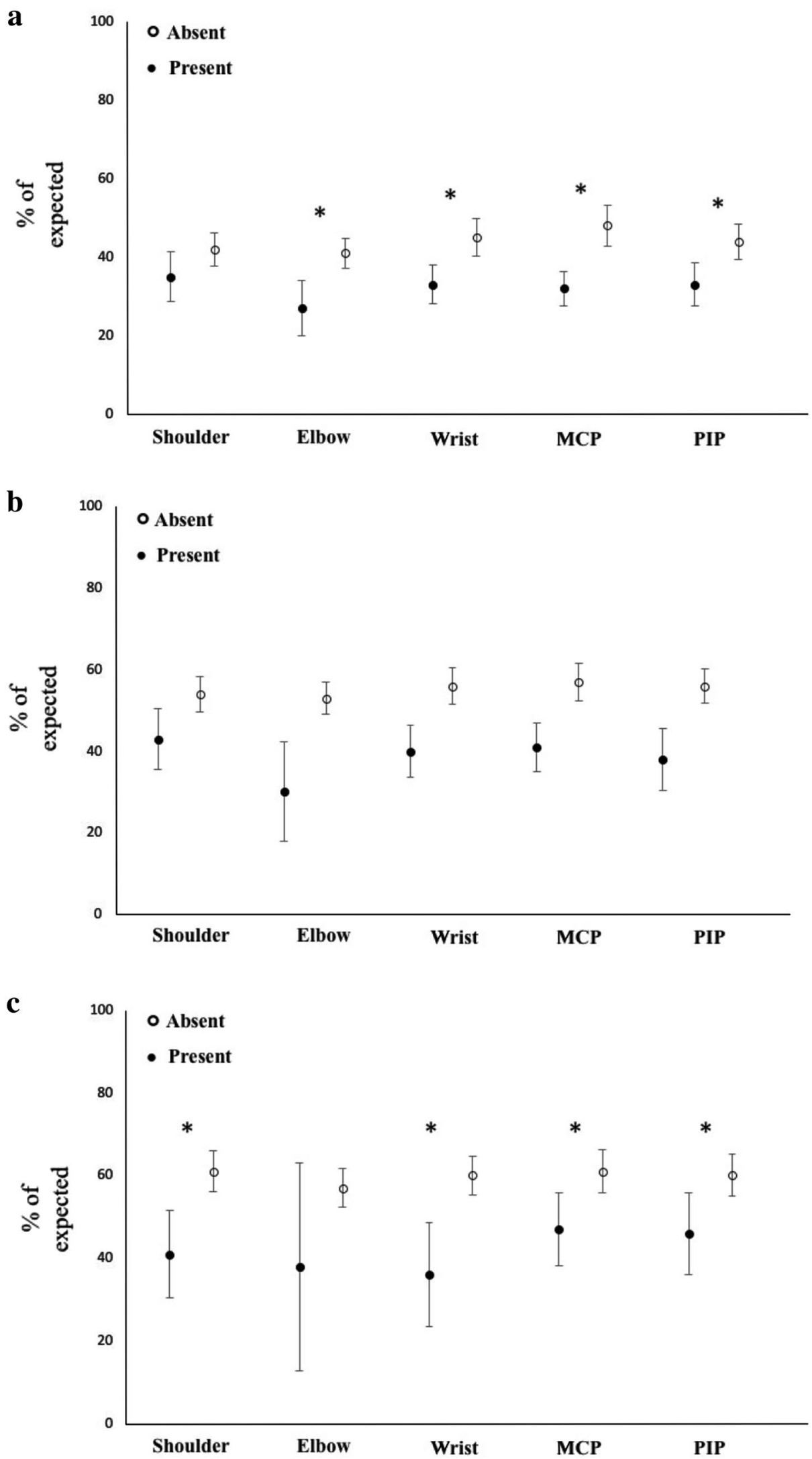
Table 3 Factors associated with average grip force (dominant hand; \% of expected value)—bivariate linear regression

\begin{tabular}{|c|c|c|c|c|c|c|c|c|c|}
\hline & \multicolumn{3}{|l|}{ Inclusion } & \multicolumn{3}{|l|}{1 year } & \multicolumn{3}{|l|}{5 years } \\
\hline & $\begin{array}{l}\text { Unstandard- } \\
\text { ized } \beta\end{array}$ & $95 \% \mathrm{CI}$ & $p$ & $\begin{array}{l}\text { Unstandard- } \\
\text { ized } \beta\end{array}$ & $95 \% \mathrm{CI}$ & $p$ & $\begin{array}{l}\text { Unstandard- } \\
\text { ized } \beta\end{array}$ & $95 \% \mathrm{CI}$ & $p$ \\
\hline $\begin{array}{l}\text { VAS pain (per } \\
\text { SD) }\end{array}$ & -10.1 & -13.4 to -6.8 & $<0.001$ & -10.7 & -14.2 to -7.2 & $<0.001$ & -10.5 & -14.8 to -6.1 & $<0.001$ \\
\hline ESR (per SD) & -6.9 & -10.4 to -3.5 & $<0.001$ & -9.2 & -13.1 to -5.2 & $<0.001$ & -7.5 & -11.9 to -3.2 & 0.001 \\
\hline $\begin{array}{c}\text { Shoulder syno- } \\
\text { vitis present }\end{array}$ & -6.1 & -20.5 to 8.4 & 0.41 & -14.3 & -31.6 to 3.0 & 0.10 & -42.7 & -85 to -0.4 & 0.048 \\
\hline $\begin{array}{l}\text { Elbow synovi- } \\
\text { tis present }\end{array}$ & -9.5 & -22.6 to 3.6 & 0.15 & -10.6 & -25.9 to 4.7 & 0.18 & -16.9 & -40 to 6.2 & 0.15 \\
\hline $\begin{array}{l}\text { Wrist synovitis } \\
\text { present }\end{array}$ & -16.0 & -23.2 to -8.9 & $<0.001$ & -10.8 & -18.5 to -3.1 & 0.006 & -19.5 & $\begin{array}{c}-28.8 \text { to } \\
-10.3\end{array}$ & $<0.001$ \\
\hline $\begin{array}{l}\text { MCP synovitis } \\
\text { present }\end{array}$ & -15.4 & -24.0 to -6.8 & 0.001 & -13.5 & -21.3 to -5.7 & 0.001 & -12.8 & -22.6 to -3 & 0.011 \\
\hline $\begin{array}{l}\text { PIP synovitis } \\
\text { present }\end{array}$ & -5.6 & -12.8 to 1.5 & 0.12 & -6.4 & -14.7 to 1.9 & 0.13 & -8.8 & -19.2 to 1.6 & 0.098 \\
\hline $\begin{array}{l}\text { No of swollen } \\
\text { MCP joints } \\
\text { (0-5; per } \\
\text { joint) }\end{array}$ & -5.9 & -8.4 to -3.5 & $<0.001$ & -6.4 & -9.3 to -3.5 & $<0.001$ & -5.4 & -8.5 to -2.2 & 0.001 \\
\hline $\begin{array}{l}\text { No of swollen } \\
\text { PIP joints } \\
(0-5 ; \text { per } \\
\text { joint })\end{array}$ & -3.2 & -5.7 to -0.7 & 0.013 & -3.9 & -7.4 to -0.4 & 0.03 & -4.9 & -9.1 to -0.7 & 0.022 \\
\hline $\begin{array}{l}\text { Tender shoul- } \\
\text { der joint } \\
\text { present }\end{array}$ & -7.3 & -15.1 to 0.4 & 0.06 & -11.1 & $\begin{array}{c}-19.8 \text { to } \\
-0.02\end{array}$ & 0.012 & -19.7 & -31.2 to -8.3 & 0.001 \\
\hline $\begin{array}{l}\text { Tender elbow } \\
\text { joint present }\end{array}$ & -14.8 & -25.8 to -3.9 & 0.008 & -22.8 & -40.8 to -4.8 & 0.014 & -19.3 & -49.6 to 11 & 0.21 \\
\hline $\begin{array}{l}\text { Tender wrist } \\
\text { joint present }\end{array}$ & -11.3 & -18.3 to -4.2 & 0.002 & -15.9 & -24.2 to -7.6 & $<0.001$ & -23.9 & $\begin{array}{c}-36.9 \text { to } \\
-10.9\end{array}$ & $<0.001$ \\
\hline $\begin{array}{l}\text { Tender MCP } \\
\text { joint present }\end{array}$ & -16.1 & -22.9 to -9.2 & $<0.001$ & -16.4 & -24.2 to -8.6 & $<0.001$ & -13.6 & -23.4 to -3.7 & 0.007 \\
\hline $\begin{array}{l}\text { Tender PIP } \\
\text { joint present }\end{array}$ & -10.8 & -17.9 to -3.7 & 0.003 & -17.6 & -26.5 to -8.8 & $<0.001$ & -13.5 & $-24,3$ to -2.7 & 0.015 \\
\hline $\begin{array}{l}\text { No of tender } \\
\text { MCP joints } \\
\text { (0-5; per } \\
\text { joint })\end{array}$ & -5.6 & -7.6 to -3.5 & $<0.001$ & -5.8 & -8.8 to -2.7 & $<0.001$ & -5.5 & -8.9 to -2.1 & 0.002 \\
\hline $\begin{array}{l}\text { No of tender } \\
\text { PIP joints } \\
(0-5 ; \text { per } \\
\text { joint })\end{array}$ & -4.1 & -6.4 to -1.9 & $<0.001$ & -6.7 & -10 to -3.3 & $<0.001$ & -6.1 & -9.9 to -2.3 & 0.002 \\
\hline
\end{tabular}

were observed at the follow-up visits after 1 and 5 years (Table 3). The presence of synovitis of the glenohumeral joint was associated with a significantly lower grip force at 5 years.

At inclusion, there was a significant interaction between the presence of wrist synovitis and elbow synovitis in the dominant hand in their impact on grip force $(p=0.02)$. At 1 year, there was significant interaction between elbow synovitis and synovitis in $\geq 1 \mathrm{MCP}$ joint and the number of MCP joints with synovitis ( $p=0.02$ and $p=0.04)$.
Furthermore, there were significant interactions between the presence of tenderness in $\geq 1$ PIP joint and in $\geq 1 \mathrm{MCP}$ joint at inclusion $(p=0.01)$ and at 5 years $(p=0.03)$. In all these cases, individuals with the involvement of several joints had lower grip force than expected, based on the contribution of each joint, except for at 5 years, where the presence of both PIP and MCP tenderness was associated with higher grip force. 
Table 4 Factors associated with average grip force (dominant hand; $\%$ of expected value) multivariate linear regression

\begin{tabular}{|c|c|c|c|}
\hline & Unstandardized $\beta$ & $95 \% \mathrm{CI}$ & $p$ \\
\hline \multicolumn{4}{|l|}{ Inclusion-multivariate linear regression ${ }^{a}$} \\
\hline VAS pain (per SD) & -5.8 & -9.3 to -2.3 & 0.001 \\
\hline ESR (per SD) & -3.6 & -6.9 to -0.3 & 0.03 \\
\hline Wrist synovitis present & -7.2 & -14.3 to 0.0 & 0.05 \\
\hline No of swollen MCP joints ( $0-5$; per joint $)$ & -2.8 & -5.3 to -0.4 & 0.02 \\
\hline Tender shoulder joint present & -1.2 & -8.1 to 5.7 & 0.73 \\
\hline Tender elbow joint present & -5.9 & -16.5 to 4.8 & 0.28 \\
\hline No of tender PIP joints ( $0-5$; per joint) & -0.7 & -2.6 to 0.4 & 0.68 \\
\hline \multicolumn{4}{|l|}{1 year-multivariate linear regression ${ }^{\mathrm{b}}$} \\
\hline VAS pain (per SD) & -5.7 & -9.8 to -1.7 & 0.006 \\
\hline ESR (per SD) & -5.1 & -9.1 to -1.2 & 0.01 \\
\hline No of swollen MCP joints ( $0-5$; per joint) & -3.3 & -6.3 to -0.3 & 0.03 \\
\hline Tender shoulder joint present & -3.6 & -11.9 to 4.6 & 0.38 \\
\hline Tender elbow joint present & -14.5 & -33.7 to 4.6 & 0.14 \\
\hline Tender wrist joint present & -3.7 & -12.6 to 5.1 & 0.41 \\
\hline No of tender PIP joints ( $0-5$; per joint $)$ & -1.9 & -5.4 to 1.6 & 0.29 \\
\hline \multicolumn{4}{|l|}{5 years-multivariate linear regression ${ }^{c}$} \\
\hline VAS pain (per SD) & -6.2 & -10.9 to -1.5 & 0.01 \\
\hline ESR (per SD) & -4.8 & -9.4 to -0.2 & 0.04 \\
\hline Shoulder synovitis present & -35.0 & -73.9 to 3.8 & 0.08 \\
\hline No of swollen MCP joints ( $0-5$; per joint $)$ & -2.2 & -5.6 to 1.2 & 0.20 \\
\hline Tender wrist joint present & -6.7 & -22.3 to 8.9 & 0.40 \\
\hline No of tender PIP joints ( $0-5$; per joint) & -6.4 & -12.1 to -0.8 & 0.03 \\
\hline
\end{tabular}

${ }^{a}$ Adjusted for all variables in the table and for the interaction terms for (1) wrist synovitis and elbow synovitis and (2) presence of tender MCP joints and presence of tender PIP joints

${ }^{\mathrm{b}}$ Adjusted for all variables in the table and for the interaction terms for elbow synovitis and MCP joint synovitis

${ }^{\mathrm{c}}$ Adjusted for all variables in the table and for the interaction terms for the presence of tender MCP joints and presence of tender PIP joints

\section{Associations between joint involvement and grip force: multivariate analyses}

In multivariate analysis, extensive MCP joint synovitis was associated with lower grip force at inclusion and at the 1-year follow-up, but not at 5 years (Table 4). There was also a borderline negative association between wrist synovitis and grip force at inclusion (Table 4). At the 5-year follow-up visit, there was a significant association between the number of tender PIP joints and reduced grip force (Table 4). VAS pain and ESR were negatively associated with grip force in multivariate models at all time points. The proportions of the variance in grip force explained by the variables in these models were $26 \%$ at inclusion, $25 \%$ at 1 year and $22 \%$ at 5 years.

Results were similar in sensitivity analyses further adjusted for current glucocorticoid use (Supplementary Table 1).

\section{Correlations with disability and global disease assessment}

Grip force (\% of expected values) correlated significantly with HAQ-DI at inclusion as well as at 1 year and 5 years ( $p=0.001$ at all time points) (Supplementary Figure 1). Similar correlations were noted for VAS global $(p=0.001$ at all time points) (Supplementary Figure 2).

\section{Discussion}

In this study of patients with early RA, MCP joint synovitis had a significant impact on grip force measured at the same outpatient visit, whereas the relative contribution of PIP synovitis to impaired grip force appeared to be less pronounced in early disease. However, at 5 years, PIP tenderness was associated with reduced grip force. The interactions for elbow synovitis with synovitis in the hand, and between 
PIP and MCP tenderness, in analyses of grip force suggest that multiple joint involvements contribute to worse hand function. In addition, both VAS pain and ESR levels were independently associated with reduced grip force, suggesting that pain and inflammation have effects on hand function beyond that mediated by local synovitis.

Joint involvement of the tested extremity, ESR and VAS pain explained $22-26 \%$ of the variation in grip force at the different time points, suggesting that other factors, such as motivation and general muscle strength, have a major impact in this context.

The correlation for grip force with disability and global disease activity [i.e. HAQ-DI and patients' global assessment (VAS)] at inclusion as well as 1 and 5 years confirms the major impact of impaired hand function in patients with RA.

The differential impact of the involvement of specific joints and joint groups on grip force likely reflects mechanical factors, and also the propensity for development of chronic arthritis in each location [29]. Expression of key developmental genes tightly controls morphogenesis of the limbs, and such gene expression is distinctly different in the four posterior digits (II-V) of the hands and feet, which are more prone to be involved in RA, compared to the anterior digit (I) [29]. The importance of such factors, and of involvement of individual finger joints, for grip force and hand disability, should be further studied.

Synovitis and tenderness of the wrist also had some impact on grip force. It is well known that wrist involvement is common in early RA [30-37] and that arthritis of the distal radio-ulnar joint is a particularly frequent cause of disability $[35,38,39]$. For example, with the impaired extension of the wrist, grip strength is decreased significantly [40]. This is likely due to reduced force of the extrinsic finger flexors when the wrist is not slightly extended [41]. In the present study, the number of involved finger joints correlated negatively with grip force, in particular the extent of MCP joint synovitis. This is compatible with data indicating that the four distal fingers of the hand all contribute significantly to grip force [40]. Joint deformities of the fingers are common in RA [6, 32, 42, 43] and swan neck deformity, in particular, is associated with low grip strength [44].

Motivation probably has a major impact on grip force. At the evaluation of grip force some people exert less than a maximal voluntary contraction with their hands. This may be intentional or unintentional. Individuals with symptoms from their upper extremity and related pain, fear of pain or fear for residual symptoms can unintentionally make a limited effort $[45,46]$. Intentional low effort can be due to secondary gain benefits, e.g. money or attention [47, 48]. Such factors are difficult to quantify and were not assessed in the present study.
Additional limitations include the lack of a control group of individuals without RA evaluated at our unit. Instead, we used age and sex-specific reference values from the literature, based on a study from Norway [28] a country with major similarities in the ethnic background and lifestyle factors to Sweden. As we used \% of expected values of grip force for each individual, we estimated the effect of other variables on age- and sex-standardized grip force.

Although the grip force measurements were partially performed by different observers, a standardized procedure was used by occupational therapists at our unit during the entire study period [26].

With the inclusion period of 1995-2005 and the followup of 5 years, the most recent data in this study are from 2010. Therefore, biologic/targeted therapy was not used as widely as today, and current treatment algorithms, including the treat to target strategy [49] were not implemented. These are important limitations of the study.

Strengths of this study include the standardized joint assessment performed by the same physician in all cases, using a structured protocol. In addition, we used standardized and established methods for assessment of grip force, performed in accordance with the recommendations from the American Society of Hand Therapists [50]. Calculation of the average of three assessments has been shown to give the highest reliability and validity in hand strength evaluation [50].

Furthermore, due to the structured longitudinal follow-up of an inception cohort from a defined catchment area, selection bias is not a major issue in this study, and the results could be generalized to patients with RA seen in clinical practice.

\section{Conclusions}

In conclusion, in patients with early RA, extensive synovitis of MCP joints was associated with reduced grip force, independently of other upper extremity joint involvement. Pain and inflammation (measured by ESR) appeared to have effects on hand function that were independent of local synovitis and joint tenderness. Throughout the observation period, reduced grip force was associated with more extensive disability and worse scores for patient global assessment of disease activity. The results underline the major importance of impaired hand function in patients with early RA.

Acknowledgements Open access funding provided by Lund University. In remembrance of Christina Book, M.D., Ph.D., who initiated this project and performed a major part of the data collection. She passed away before the preparation of this manuscript.

Author contributions All authors contributed to the study conception and design. Data collection was performed by MR and IW. Statistical analyses were performed by MR and CT. SH and LJ contributed 
to the interpretation and analysis of the results. The first draft of the manuscript was written by MR and CT. All authors commented on previous versions of the manuscript. All authors read and approved the final manuscript.

Funding This work was supported by The Swedish Research Council (Grant number 2015-02228), The Swedish Rheumatism Association (Grant number R-664091) and Lund University (Grant number ALFSKANE-446501).

\section{Compliance with ethical standards}

Conflict of interest The authors declare that they have no competing interests.

Ethical approval All procedures performed in studies involving human participants were in accordance with the ethical standards of the regional research committee (Regional Ethical Review Board for southern Sweden, Lund, Sweden-LU 410-94, January 30. 1995 and LU 311-02, June 10, 2002) and with the 1964 Helsinki declaration and its later amendments or comparable ethical standards.

Ethical statement All patients gave their written informed consent to participate, and the study was approved by the Regional Ethical Review Board for southern Sweden (Lund, Sweden).

\section{Consent for publication Not applicable}

Availability of data and materials The datasets generated and/or analysed during the current study are not publicly available due to Swedish legislation (the General Data Protection Regulation), but a limited and fully anonymised dataset containing the individual patient data that support the main analyses is available from the corresponding author on reasonable request.

Open Access This article is distributed under the terms of the Creative Commons Attribution 4.0 International License (http://creativeco mmons.org/licenses/by/4.0/), which permits unrestricted use, distribution, and reproduction in any medium, provided you give appropriate credit to the original author(s) and the source, provide a link to the Creative Commons license, and indicate if changes were made.

\section{References}

1. Scott DL, Wolfe F, Huizinga TW (2010) Rheumatoid arthritis. Lancet 376(9746):1094-1108

2. Sebastin SJ, Chung KC (2011) Reconstruction of digital deformities in rheumatoid arthritis. Hand Clin 27(1):87-104

3. Bodur H, Yilmaz O, Keskin D (2006) Hand disability and related variables in patients with rheumatoid arthritis. Rheumatol Int 26(6):541-544

4. Escalante A, Haas RW, del Rincon I (2005) A model of impairment and functional limitation in rheumatoid arthritis. BMC Musculoskelet Disord 6:16

5. Horsten NC, Ursum J, Roorda LD, van Schaardenburg D, Dekker J, Hoeksma AF (2010) Prevalence of hand symptoms, impairments and activity limitations in rheumatoid arthritis in relation to disease duration. J Rehabil Med 42(10):916-921

6. Eberhardt KB, Fex E (1995) Functional impairment and disability in early rheumatoid arthritis-development over 5 years. J Rheumatol 22(6):1037-1042
7. Hakkinen A, Hannonen P, Hakkinen K (1995) Muscle strength in healthy people and in patients suffering from recent-onset inflammatory arthritis. Br J Rheumatol 34(4):355-360

8. Bjork M, Thyberg I, Haglund L, Skogh T (2006) Hand function in women and men with early rheumatoid arthritis. A prospective study over three years (the Swedish TIRA project). Scand J Rheumatol 35(1):15-19

9. Bjork MA, Thyberg IS, Skogh T, Gerdle BU (2007) Hand function and activity limitation according to health assessment questionnaire in patients with rheumatoid arthritis and healthy referents: 5-year followup of predictors of activity limitation (The Swedish TIRA Project). J Rheumatol 34(2):296-302

10. Brorsson S, Nilsdotter A, Pedersen E, Bremander A, Thorstensson C (2012) Relationship between finger flexion and extension force in healthy women and women with rheumatoid arthritis. J Rehabil Med 44(7):605-608

11. Bilberg A, Bremell T, Balogh I, Mannerkorpi K (2015) Significantly impaired shoulder function in the first years of rheumatoid arthritis: a controlled study. Arthritis Res Ther 17:261

12. Rydholm M, Book C, Wikstrom I, Jacobsson L, Turesson C (2018) Course of grip force impairment in patients with early rheumatoid arthritis over the first five years after diagnosis. Arthritis Care Res 70(4):491-498

13. Björk M, Thyberg I, Lindstrand J, Bodin N, Rosengren J, Nordenskiöld U et al (2015) Development of measuring devices for evaluating hand force in rheumatoid arthritis. Ann Rheum Dis 74:S1334

14. Fries JF, Spitz P, Kraines RG, Holman HR (1980) Measurement of patient outcome in arthritis. Arthritis Rheumatol 23(2):137-145

15. Buchbinder R, Bombardier C, Yeung M, Tugwell P (1995) Which outcome measures should be used in rheumatoid arthritis clinical trials? Clinical and quality-of-life measures' responsiveness to treatment in a randomized controlled trial. Arthritis Rheumatol 38(11):1568-1580

16. Shimose R, Matsunaga A, Muro M (2011) Effect of submaximal isometric wrist extension training on grip strength. Eur J Appl Physiol 111(3):557-565

17. Claudon L (1998) Evaluation of grip force using electromyograms in isometric isotonic conditions. Int J Occup Saf Ergon 4(2):169-184

18. Mogk JP, Keir PJ (2003) The effects of posture on forearm muscle loading during gripping. Ergonomics 46(9):956-975

19. Duque J, Masset D, Malchaire J (1995) Evaluation of handgrip force from EMG measurements. Appl Ergon 26(1):61-66

20. Bohannon RW (1998) Hand-grip dynamometry provides a valid indication of upper extremity strength impairment in home care patients. J Hand Ther 11(4):258-260

21. Book C, Karlsson MK, Akesson K, Jacobsson LT (2009) Early rheumatoid arthritis and body composition. Rheumatology (Oxford) 48(9):1128-1132

22. Tanaka E, Saito A, Kamitsuji S, Yamada T, Nakajima A, Taniguchi A et al (2005) Impact of shoulder, elbow, and knee joint involvement on assessment of rheumatoid arthritis using the American College of Rheumatology Core Data Set. Arthritis Rheumatol 53(6):864-871

23. Mathieux R, Marotte H, Battistini L, Sarrazin A, Berthier M, Miossec P (2009) Early occupational therapy programme increases hand grip strength at 3 months: results from a randomised, blind, controlled study in early rheumatoid arthritis. Ann Rheum Dis 68(3):400-403

24. Lamb SE, Williamson EM, Heine PJ, Adams J, Dosanjh S, Dritsaki $M$ et al (2015) Exercises to improve function of the rheumatoid hand (SARAH): a randomised controlled trial. Lancet 385(9966):421-429 
25. Arnett FC, Edworthy SM, Bloch DA, McShane DJ, Fries JF, Cooper NS et al (1988) The American Rheumatism Association 1987 revised criteria for the classification of rheumatoid arthritis. Arthritis Rheumatol 31(3):315-324

26. Nordenskiold UM, Grimby G (1993) Grip force in patients with rheumatoid arthritis and fibromyalgia and in healthy subjects. A study with the Grippit instrument. Scand J Rheumatol 22(1):14-19

27. Svensson E, Waling K, Hager-Ross C (2008) Grip strength in children: test-retest reliability using Grippit. Acta Paediatrica (Oslo, Norway: 1992) 97(9):1226-1231

28. Nilsen T, Hermann M, Eriksen CS, Dagfinrud H, Mowinckel P, Kjeken I (2012) Grip force and pinch grip in an adult population: reference values and factors associated with grip force. Scand $\mathbf{J}$ Occup Ther 19(3):288-296

29. Ospelt C, Frank-Bertoncelj M (2017) Why location matterssite-specific factors in rheumatic diseases. Nat Rev Rheumatol 13(7):433-442

30. Trieb K (2008) Treatment of the wrist in rheumatoid arthritis. J Hand Surg 33(1):113-123

31. Rizzo M, Cooney WP 3rd (2011) Current concepts and treatment for the rheumatoid wrist. Hand Clin 27(1):57-72

32. Fex E, Jonsson K, Johnson U, Eberhardt K (1996) Development of radiographic damage during the first 5-6 yr of rheumatoid arthritis. A prospective follow-up study of a Swedish cohort. Br J Rheumatol 35(11):1106-1115

33. Kim SJ, Jung KA (2007) Arthroscopic synovectomy in rheumatoid arthritis of wrist. Clin Med Res. 5(4):244-250

34. Feldkamp G (2008) Possibilities of wrist arthroscopy. Even for patients with arthritis? Z Rheumatol 67(6):478-484

35. Leak RS, Rayan GM, Arthur RE (2003) Longitudinal radiographic analysis of rheumatoid arthritis in the hand and wrist. J Hand Surg 28(3):427-434

36. Kanazawa T, Nishino J, Tohma S, Tanaka S (2013) Analysis of the affected joints in rheumatoid arthritis patients in a large Japanese cohort. Mod Rheumatol 23(1):44-49

37. Shim JW, Park MJ (2017) Arthroscopic synovectomy of wrist in rheumatoid arthritis. Hand Clin 33(4):779-785

38. Bigorre N, Saint Cast Y, Cesari B, Rabarin F, Raimbeau G (2016) Intermediate term evaluation of the Eclypse distal radio-ulnar prosthesis for rheumatoid arthritis. A report of five cases. Orthop Traumatol Surg Res 102(3):345-349

39. Murray PM (2011) Current concepts in the treatment of rheumatoid arthritis of the distal radioulnar joint. Hand Clin 27(1):49-55
40. Gulke J, Scholl H, Kapapa T, Geyer T, Mentzel M, Wachter NJ (2016) Simulated total wrist fusion and its influence on hand grip function. Handchir Mikrochir Plast Chir 48(5):281-289

41. Suzuki T, Kunishi T, Kakizaki J, Iwakura N, Takahashi J, Kuniyoshi K (2012) Wrist extension strength required for power grip: a study using a radial nerve block model. J Hand Surg Eur 37(5):432-435

42. Eberhardt K, Johnson PM, Rydgren L (1991) The occurrence and significance of hand deformities in early rheumatoid arthritis. $\mathrm{Br}$ J Rheumatol 30(3):211-213

43. Johnsson PM, Eberhardt K (2009) Hand deformities are important signs of disease severity in patients with early rheumatoid arthritis. Rheumatology (Oxford) 48(11):1398-1401

44. Dias JJ, Singh HP, Taub N, Thompson J (2013) Grip strength characteristics using force-time curves in rheumatoid hands. J Hand Surg Eur 38(2):170-177

45. van Wilgen CP, Akkerman L, Wieringa J, Dijkstra PU (2003) Muscle strength in patients with chronic pain. Clin Rehabil 17(8):885-889

46. Robinson ME, Dannecker EA (2004) Critical issues in the use of muscle testing for the determination of sincerity of effort. Clin $\mathbf{J}$ Pain 20(6):392-398

47. Fishbain DA, Rosomoff HL, Cutler RB, Rosomoff RS (1995) Secondary gain concept: a review of the scientific evidence. Clin J Pain 11(1):6-21

48. Fishbain DA, Cutler R, Rosomoff HL, Rosomoff RS (1999) Chronic pain disability exaggeration/malingering and submaximal effort research. Clin J Pain 15(4):244-274

49. Smolen JS, Aletaha D, Bijlsma JW, Breedveld FC, Boumpas D, Burmester G et al (2010) Treating rheumatoid arthritis to target: recommendations of an international task force. Ann Rheum Dis 69(4):631-637

50. Mathiowetz V, Kashman N, Volland G, Weber K, Dowe M, Rogers S (1985) Grip and pinch strength: normative data for adults. Arch Phys Med Rehabil 66(2):69-74

Publisher's Note Springer Nature remains neutral with regard to jurisdictional claims in published maps and institutional affiliations. 